\title{
KAPASITAS GESER BALOK BETON BERTULANG HVFA MEMADAT SENDIRI DENGAN KADAR FLY ASH 60\% TERHADAP BETON NORMAL
}

\author{
Arjun Prasetyo ${ }^{1)}$, Agus Setiya Budi' ${ }^{2}$, Stefanus Adi Kristiawan ${ }^{3)}$ \\ 1) Mahasiswa Prodi Teknik Sipil, Fakultas Teknik, Universitas Sebelas Maret \\ 2),3) Pengajar Prodi Teknik Sipil, Fakultas Teknik, Universitas Sebelas Maret \\ J1. Ir. Sutami 36A, Kentingan Surakarta 57126; Telp 0271-634524. \\ Email: arjunprasetyo310@gmail.com
}

\begin{abstract}
Fly ash are the remnants of coal combustion in the form of fine particles and an inorganic material is formed from mineral material change since the combustion of the coal combustion process. Chemical properties fly ash contains silica (SiO2) is high, the nature is what makes fly ash is used as a cement replacement materials, so the utilization of fly ash as a cement substitute materials can reduce the production of cement. This research will examine the shear capacity of HVFA - SCC reinforced concrete beams with 60\% fly ash content and then will be compared with normal concrete beams. The specimen used in this research is a reinforced concrete beam with cross-sectional area of $10 \mathrm{~cm} \times 15 \mathrm{~cm}$ with length of $150 \mathrm{~cm}$. Shear capacity test using a loading frame by performing two loading points at 1/3 span. From this test, we will get the load-deflection relationship chart, the calculation of shear capacity of concrete beams HVFA-SCC 60. Based on shear capacity test of concrete beams, the value of HVFA-SCC with $60 \%$ fly ash content is greater than normal concrete beams tested at 28 days, which has value $26.125 \mathrm{kN}$ for HVFA-SCC 60\% and 21.500 kN for normal concrete.
\end{abstract}

Keywords: fly ash, hvfa-scc, shear capacity.

\begin{abstract}
Abstrak
Fly ash adalah sisa-sisa pembakaran batu bara yang berbentuk partikel halus dan merupakan bahan anorganik yang terbentuk dari perubahan bahan mineral karena proses pembakaran dari proses pembakaran batubara. Sifat kimia fly ash memiliki kandungan silica $\left(\mathrm{SiO}_{2}\right)$ yang tinggi, sifat inilah yang menjadikan fly ash digunakan sebagai bahan pengganti semen, sehingga pemanfataan fly ash sebagai bahan pengganti semen dapat mengurangi produksi semen. Penelitian ini akan mengkaji seberapa besar kapasitas geser balok beton bertulang High Volume Fly Ash - Self Compacting Concrete (HVFA - SCC) dengan kadar fly ash $60 \%$ dan kemudian akan dibandingkan dengan balok beton normal. Benda uji yang digunakan balok beton bertulang dengan luas penampang $10 \mathrm{~cm}$ × $15 \mathrm{~cm}$ dengan panjang $150 \mathrm{~cm}$. Pengujian kapasitas geser menggunakan alat loading frame dengan melakukan 2 titik pembebanan pada 1/3 bentang balok. Dari pengujian ini akan didapatkan grafik hubungan beban-lendutan serta perhitungan kapasitas geser balok beton HVFA-SCC $60 \%$. Berdasarkan hasil penelitian ini kapasitas geser pengujian balok beton HVFA-SCC 60\% memiliki nilai yang lebih besar dibandingkan dengan kapasitas geser hasil pengujian balok beton normal yang diuji pada umur 28 hari yakni sebesar 26,125 kN untuk HVFA-SCC $60 \%$ dan 21,500 kN untuk beton normal.
\end{abstract}

Kata Kunci : fly ash, hvfa-scc, kapasitas geser.

\section{PENDAHULUAN}

Pada era modern sekarang ini, pembangunan infrastruktur telah berkembang pesat. Dalam pelaksanannya, material beton sering digunakan sebagai pilihan untuk bahan dasar konstruksi. Penggunaan semen dalam pembuatan beton normal merupakan salah satu hal pemicu terjadinya Global Warming. Hal ini disebabkan dari proses produksi 1000 kg menghasilkan emisi gas buang $\mathrm{CO}_{2}$ sebesar $820 \mathrm{~kg}$ (IEA, 2007). Pada tahun 2018 diperkirakan produksi semen menyumbang sekitar $7 \%$ dari emisi $\mathrm{CO}_{2}$ global (Energies, 2019).

Untuk mengurangi pencemaran emisi $\mathrm{CO}_{2}$ dari produksi dan penggunaan semen yang berlebihan dapat dilakukan penggunaan fly ash sebagai pengganti semen dalam pembuatan beton. Fly ash atau abu terbang adalah sisa-sisa pembakaran batu bara yang berbentuk partikel halus dan merupakan bahan anorganik yang terbentuk dari perubahan bahan mineral karena proses pembakaran dari proses pembakaran batubara. Sifat kimia fly ash memiliki kandungan silica $\left(\mathrm{SiO}_{2}\right)$ yang tinggi, sifat inilah yang menjadikan fly ash digunakan sebagai bahan pengganti semen. Fly ash bersifat pozzolanic yang bereaksi secara kimia dengan kalsium hidroksida pada temperatur biasa membentuk senyawa bersifat cementitious (bersifat mengikat).

penggunaan fly ash sebagai bahan pengganti semen dalam pembuatan beton dalam kadar yang tinggi atau disebut dengan High Volume Fly Ash (HVFA) Concrete. High Volume Fly Ash (HVFA) Concrete merupakan beton yang menggunakan setidaknya $50 \%$ kadar fly ash sebagai bahan pengganti semen dalam campurannya. Penggunaan fly ash dapat meningkatkan kemudahan kerja (workability) dan daya tahan (durability) pada beton (Marthinus, 2015). Dalam konstruksi struktur bertulang pada bangunan tinggi dan kompleks menimbulkan pekerjaan beton yang khusus, diantaranya berkaitan dengan penuangan dan pengecoran beton pada bekisting. Dalam kasus ini sangat diperlukan sifat self-compactibility beton segar yang digunakan, untuk itu perlu ditambahkan zat kimia superplasticizer yang 
berfungsi untuk meningkatkan kemudahan pekerjaan beton segar (workability) saat penuangan dan pemadatan serta menyebarkan adukan beton tanpa terjadi penggumpalan. Teknologi beton ini disebut dengan istilah Self Compacting Concrete (SCC), beton ini memiliki sifat yang dapat mengalir mengisi ruang yang ada dan memadat dengan sendirinya dengan sedikit bantuan vibrator atau bahkan tidak menggunakan vibrator.

Beton memiliki kuat tekan yang sangat baik sedangkan untuk kuat tarik beton cenderung lemah. Dalam pengaplikasiannya, beton diberi tulangan baja untuk mengatasi kelemahan akan kuat tariknya, karena baja sendiri memiliki kuat tarik yang tinggi. Penelitian ini akan mengkaji seberapa besar kapasitas geser balok beton bertulang High Volume Fly Ash - Self Compacting Concrete (HVFA - SCC) dengan kadar fly ash $60 \%$ dan kemudian akan dibandingkan dengan balok beton normal pada umur 28 hari.

\section{LANDASAN TEORI}

\section{Self Compacting Concrete (SCC)}

Self-Compacting Concrete (SCC) pertama kali dikembangkan di Jepang sekitar tahun 1980-an untuk mencapai struktur beton yang memiliki daya tahan tinggi. Sejak itu, berbagai penelitian telah dilakukan untuk mencapai desain campuran yang rasional untuk beton standar, yang sebanding dengan beton normal. Self Compacting Concrete didefinisikan sebagai beton yang tidak membutuhkan tambahan getaran baik di dalam atau di luar untuk proses pemadatan. SCC dapat memadatkan dirinya sendiri karena berat sendirinya dan mengalami deaerasi hampir sepenuhnya saat mengalir dalam bekisting. Pada struktur yang menggunakan perkuatan dengan presentase yang tinggi, campuran beton juga dapat mengisi semua ruang dan celah sepenuhnya. SCC mengalir seperti "madu" dan memiliki permukaan yang merata secara horizontal setelah penuangan (Frank Dehn, 2000).

Secara umum Self Compacting Concrete merupakan varian beton yang memiliki tingkat derajat pengerjaan (workability) tinggi dan juga memiliki kekuatan awal yang besar, sehingga membutuhkan faktor air semen yang rendah.

\section{High Volume Fly Ash (HVFA)}

High volume fly ash concrete (HVFAC) adalah beton yang menggunakan fly ash sebagai bahan pozzolanic dan digunakan bersamaan dengan semen dengan persentase $f l y$ ash $50 \%$ atau lebih dari berat total binder. Kelebihan beton tersebut adalah ramah lingkungan, ekonomis, memperlambat setting time, meningkatkan workability, durability, dan diharapkan meningkatkan kekuatan dari beton (Stefanus dan Howard, 2010).

\section{High Volume Fly Ash - Self Compacting Concrete (HVFA-SCC)}

HVFA-SCC adalah perpaduan teknologi antara HVFAC dan SCC dimana pembuatan beton dibuat dengan kadar fly ash minimal 50\% dari berat binder dan memiliki sifat-sifat beton segar sama seperti SCC biasa. Penggunaan fly ash dimaksudkan untuk meningkatkan workability beton segar dan juga mengisi rongga-rongga yang ada pada beton. HVFA - SCC dapat mengalir dan memadat dengan memanfaatkan berat sendiri, sehingga tidak diperlukan proses pemadatan dengan menggunakan alat (Karina, 2018).

\section{Kapasitas Geser Balok}

Kuat geser dalam balok beton selalu diikuti oleh desak dan tarik oleh lendutan. Pengaruh-pengaruh geser yang ditumbulkan merupakan akibat dari torsi dan kombinasi torsi dengan lentur (Chu-kia Wang dan Charles G. Salmon, 1983).

Pada sampel uji penelitian ini hanya menggunakan tulangan utama tanpa adanya tulangan sengkang, hal ini bertujuan untuk memastikan pada saat pengujian balok akan mengalami gagal geser. Untuk itu kekuatan geser nominal $\left(V_{n}\right)$ hanya dari kontribusi kekuatan geser beton $\left(V_{c}\right)$.

$$
\begin{gathered}
\mathrm{V}_{\mathrm{u}} \leq \phi \mathrm{V}_{\mathrm{n}} \\
\mathrm{V}_{\mathrm{n}}=\mathrm{V}_{\mathrm{s}}+\mathrm{V}_{\mathrm{c}}
\end{gathered}
$$

Karena $V_{\mathrm{s}}=0$ maka,

$$
\mathrm{V}_{\mathrm{n}}=\mathrm{V}_{\mathrm{c}}
$$

Menurut ACI Code 318-14, Vc dapat dihitung menggunakan persamaan:

$$
V_{c}=\left(0,16 \sqrt{f^{\prime} c}+17 \rho_{w} \frac{V_{u} d}{M_{u}}\right) b_{w} d
$$

\section{METODE}

Metode penelitian yang digunakan dalam penelitian ini adalah metode eksperimental. Metode yang digunakan berupa penelitian yang dilakukan berdasarkan percobaan benda uji agar didapatkan data atau hasil yang diselidiki dalam kondisi terkontrol. Penelitian diharuskan dilakukan secara sistematis agar mendapatkan hasil penelitian yang valid dan dapat dipertanggungjawabkan. 
Pada penelitian ini benda uji yang digunakan adalah balok beton bertulang dengan luas penampang $10 \mathrm{~cm} \times 15$ $\mathrm{cm} \times 150 \mathrm{~cm}$ yang terdiri dari balok beton normal dan balok beton tipe HVFA-SCC dengan kadar fly ash $60 \%$ umur 28 hari. Model benda uji dapat dilihat pada Gambar 1 sebagai berikut :

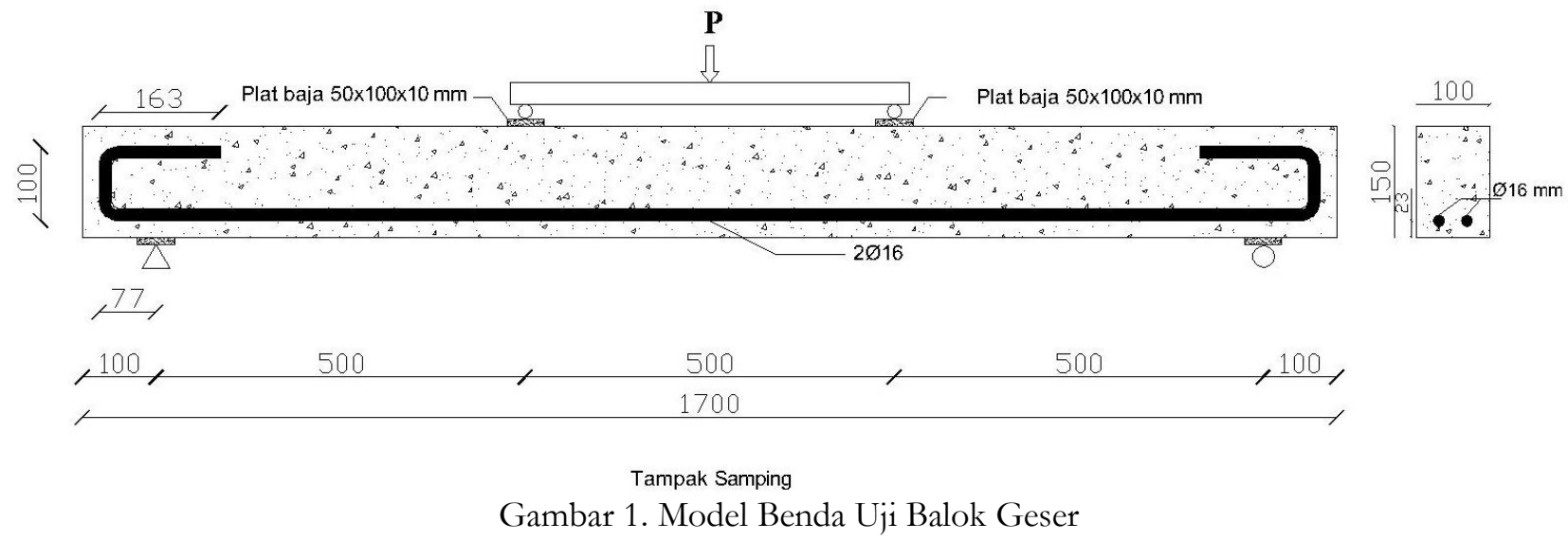

Pengujian dilakukan dengan memberikan beban pada 2 titik pembebanan di $1 / 3$ bentang. Setting up alat pengujian dapat dilihat pada Gambar 2 sebagai berikut :

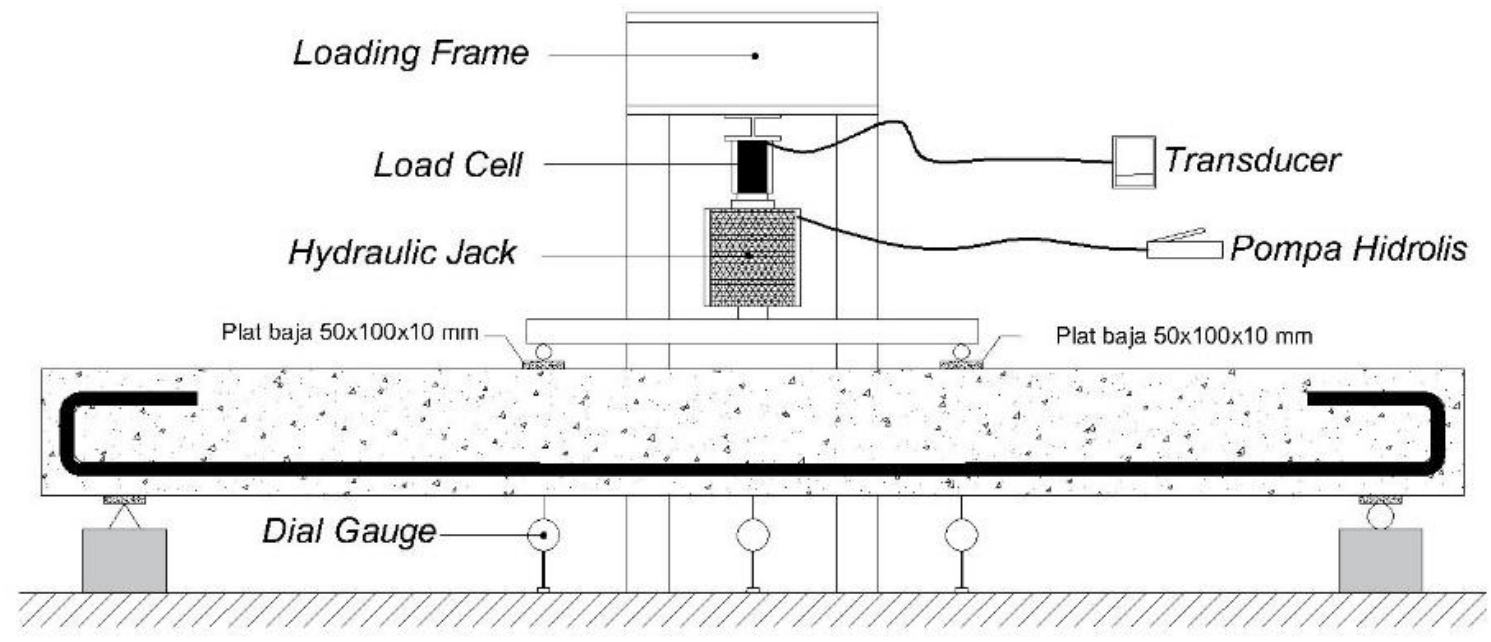

Gambar 2. Setting Up Alat Pengujian Balok (Standar ASTM Vol. 04.02)

\section{HASIL DAN PEMBAHASAN}

\section{Hasil Pengujian Bahan}

Pengujian material agregat halus meliputi pengujian kadar lumpur, kandungan zat organik, specific gravity. Adapun hasil pengujian agregat halus disajikan dalam Tabel 1.

Tabel 1. Hasil Pengujian Agregat Halus

\begin{tabular}{lccc}
\hline \multicolumn{1}{c}{ Jenis Pengujian } & Hasil Pengujian & Standar & Keterangan \\
\hline Absorbtion & $1,9368 \%$ & - & - \\
\hline Apparent Specific Gravity & $2,6272 \mathrm{gr} / \mathrm{cm}^{3}$ & - & - \\
\hline Bulk Specific Gravity & $2,500 \mathrm{gr} / \mathrm{cm}^{3}$ & - & - \\
\hline Kandungan Zat Organik & Kuning Muda & Kuning Muda & Memenuhi syarat \\
\hline Kandungan Lumpur & $4,5 \%$ & Maksimal $5 \%$ & Memenuhi syarat \\
\hline Bulk Specific SSD & $2,5484 \mathrm{gr} / \mathrm{cm}^{3}$ & $2,5-2,7 \mathrm{gr} / \mathrm{cm}^{3}$ & Memenuhi syarat \\
\hline
\end{tabular}

Pengujian material agregat kasar meliputi pengujian berat jenis (specific gravity), dan keausan agregat (abrasi). Adapun hasil pengujian agregat kasar disajikan dalam Tabel 2.

Table 2. Hasil Pengujian Agregat Kasar

Jenis Pengujian
Hasil Pengujian
Kesimpulan 


\begin{tabular}{lccc}
\hline Absorbtion & $2,1 \%$ & - & - \\
\hline Apparent Specific Gravity & $2,6478 \mathrm{gr} / \mathrm{cm}^{3}$ & - & - \\
\hline Bulk Specific Gravity & $2,5084 \mathrm{gr} / \mathrm{cm}^{3}$ & - & - \\
\hline Bulk Specific SSD & $2,5610 \mathrm{gr} / \mathrm{cm}^{3}$ & $2,5-2,7 \mathrm{gr} / \mathrm{cm}^{3}$ & Memenuhi syarat \\
\hline Keausan Agregat & $26,92 \%$ & $<50 \%$ & Memenuhi syarat \\
\hline
\end{tabular}

Pengujian kuat tarik baja dilaksanakan di Laboratorium Material Program Studi Teknik Mesin Fakultas Teknik, Universitas Sebelas Maret Surakarta, dengan menggunakan mesin UTM (Universal Testing Machine) sesuai dengan standar ASTM. Baja yang digunakan merupakan potongan tulangan baja polos yang akan digunakan sebagai tulangan pada balok beton bertulang dengan diameter tulangan $\varnothing 16 \mathrm{~mm}$ dengan panjang $30 \mathrm{~cm}$ yang dibubut sepanjang Lo 6,5 cm dan diameter setelah dibubut $13 \mathrm{~mm}$. Adapun hasil pengujian kuat tarik baja disajikan pada Tabel 3.

Tabel 3. Hasil Pengujian Kuat Tarik Baja Ø16 mm

\begin{tabular}{|c|c|c|c|c|c|c|}
\hline $\begin{array}{c}\text { Benda } \\
\text { Uji }\end{array}$ & $\begin{array}{c}\mathrm{D} \\
(\mathrm{mm})\end{array}$ & $\begin{array}{c}\text { As } \\
\left(\mathrm{mm}^{2}\right)\end{array}$ & $\mathbf{P}_{\text {leleh }}(\mathbf{N})$ & $\mathbf{P}_{\text {maks }}(\mathbf{N})$ & Fy (MPa) & $\begin{array}{c}\text { Fu } \\
(\mathrm{MPa})\end{array}$ \\
\hline $\mathrm{A}$ & 16 & \multirow{2}{*}{132,73} & 52514.20 & 80300 & 395,64 & 604,97 \\
\hline B & 16 & & 54453,42 & 83740 & 410,25 & 630,89 \\
\hline \multicolumn{5}{|c|}{ Rata-rata } & 402,95 & 617.93 \\
\hline
\end{tabular}

\section{Hasil Pengujian Beton Segar}

Pengujian beton segar HVFA-SCC 60\% terdiri dari Flow Table Test, L-Box Test, dan $V$-funnel Test, sedangkan beton normal dilakukan pengujian slump. Hasil pengujian beton segar tersebut disajikan dalam Tabel 4 hingga Tabel 6 .

Tabel 4. Hasil Pengujian Flow Table Test HVFA-SCC 60\%

\begin{tabular}{cccccccc}
\hline & \multicolumn{3}{c}{ Flow Table Test } & \multicolumn{3}{c}{ Syarat menurut } \\
Kode & $\mathbf{d 1}$ & $\begin{array}{c}\text { Diameter } \\
\mathbf{d} 2\end{array}$ & $\begin{array}{c}\mathbf{d}_{\text {rata-rata }} \\
(\mathbf{m m})\end{array}$ & $\begin{array}{c}\text { Waktu } \\
\mathbf{t}_{\mathbf{5}} \\
(\mathbf{d t})\end{array}$ & $\begin{array}{c}\mathbf{T}_{\mathbf{5 0}} \\
\mathbf{( s )}\end{array}$ & $\begin{array}{c}\mathbf{d}_{\text {rata-rata }} \\
(\mathbf{m m})\end{array}$ & Keterangan \\
\hline $\begin{array}{c}\text { HVFA } \\
60 \%\end{array}$ & 700 & 700 & 700 & 3,11 & $2-5$ & $650-800$ & Memenuhi \\
\hline
\end{tabular}

Table 5. Hasil Pengujian L-Box HVFA-SCC 60\%

\begin{tabular}{cccccc}
\hline Kode & \multicolumn{3}{c}{ L-Box Type } \\
& $\begin{array}{c}\mathbf{h}_{1} \\
(\mathbf{m m})\end{array}$ & $\begin{array}{c}\mathbf{h}_{2} \\
(\mathbf{m m})\end{array}$ & $\mathbf{h}_{2} / \mathbf{h}_{1}$ & $\begin{array}{c}\text { Syarat } \\
\left(\mathbf{h}_{2} / \mathbf{h}_{\mathbf{1}}\right)\end{array}$ & Keterangan \\
\hline $\begin{array}{c}\text { HVFA } \\
60 \%\end{array}$ & 90 & 85 & 0,9444 & $0,8-1,0$ & Memenuhi \\
\hline
\end{tabular}

Tabel 6. Hasil Pengujian V-Funnel HVFA-SCC 60\%

\begin{tabular}{cccc}
\hline Kode & T (dt) & Syarat $(\mathbf{d t})$ & Keterangan \\
\hline HVFA & 9,57 & $8-12$ & Memenuhi \\
$60 \%$ & & & \\
\hline
\end{tabular}

Hasil pengujian beton segar HVFA-SCC 60\% seluruhnya sudah memenuhi syarat beton self compacting concrete berdasarkan EFNARC Specification and Guidelines for Self - Compacting Concrete.

Nilai slump yang didapat pada pengujian beton normal adalah 10,5 cm. Berdasarkan PBI 1971 nilai slump yang disyaratkan untuk beton normal adalah $7.5-15 \mathrm{~cm}$. Maka nilai slump dari beton normal memenuhi syarat.

\section{Hasil Pengujian Kapasitas Geser Balok}


Pada pengujian balok beton bertulang HVFA-SCC 60\% dan balok beton normal didapatkan keruntuhan balok dikarenakan gagal geser, yaitu kapasitas geser balok lebih kecil dibandingkan dengan kapasitas lenturnya. Pembacaan lendutan dilakukan setiap interval pembebanan $0,5 \mathrm{kN}$. Hubungan beban dan lendutan rata-rata hasil pengujian kapasitas geser balok beton bertulang normal dan balok beton bertulang HVFA-SCC 60\% dapat dilihat pada gambar 3 dan 4 dibawah ini.

\section{HUBUNGAN BEBAN-LENDUTAN BALOK BETON BERTULANG HVFA-SCC $60 \%$}

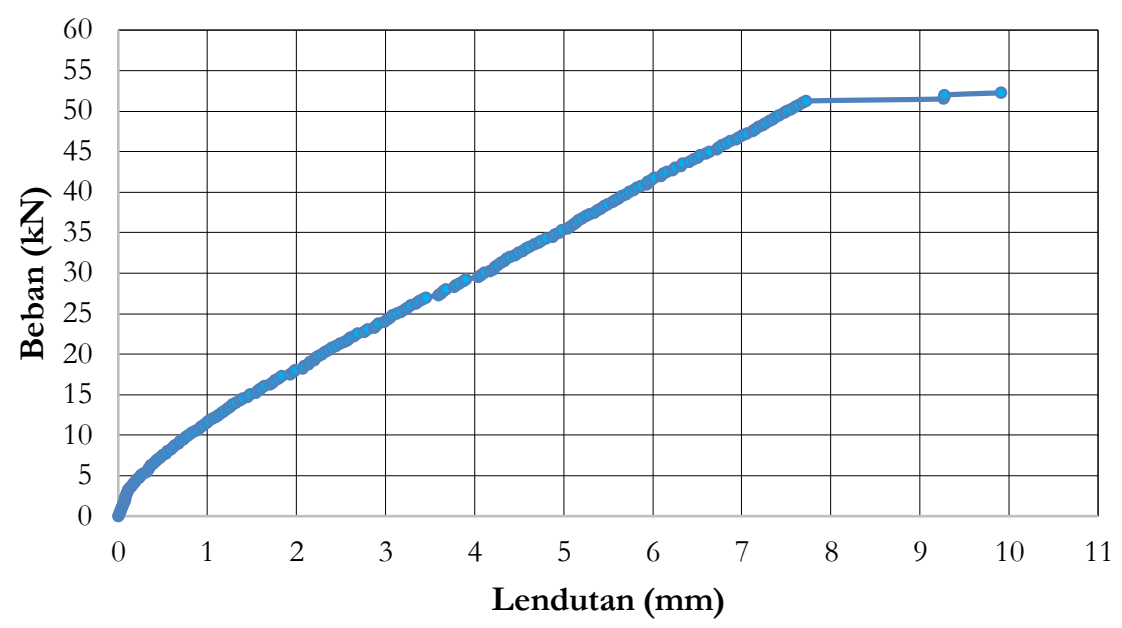

Gambar 3. Hubungan Beban-Lendutan Balok Beton Bertulang HVFA-SCC 60\%

\section{HUBUNGAN BEBAN-LENDUTAN BALOK BETON BERTULANG NORMAL}

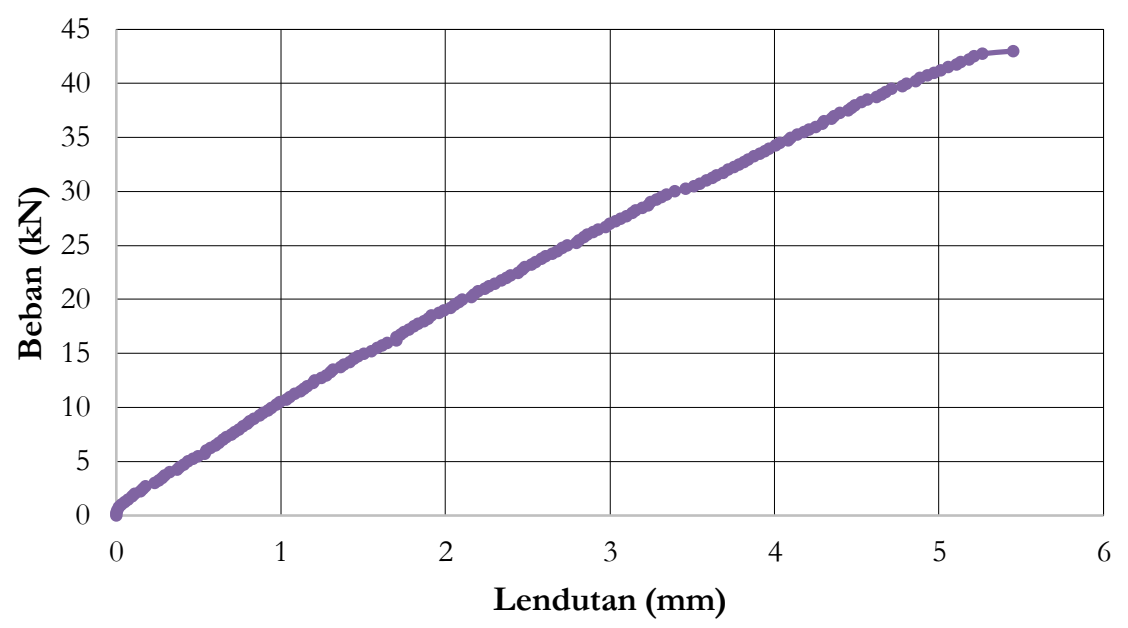

Gambar 4. Hubungan Beban-Lendutan Balok Beton Bertulang Normal

Berdasarkan grafik diatas balok HVFA-SCC 60\% yang diuji pada umur 28 hari memiliki nilai lendutan maksimum dan beban maksimum yang lebih besar dibandingkan balok beton normal yang diuji pada umur 28 hari.

Serta pada grafik hubungan beban-lendutan balok beton bertulang HVFA-SCC 60\% dan balok beton normal menunjukan bahwa besar lendutan yang terjadi akan bertambah seiring dengan kenaikan pada pembebanan yang dilakukan. Pada awal pembebanan hubungan beban dan lendutan menunjukan hubungan yang linear, yaitu kenaikan lendutan selalu proposional untuk tiap kenaikan beban. Namun, yang membedakan hubungan beban dan lendutan antara balok HVFA-SCC 60\% dan balok beton normal yaitu pada grafik balok beton normal kenaikan lendutan terhadap pembebanan menunjukan hubungan yang linier dari awal hingga akhir saat balok mengalami 
runtuh. Sedangkan pada balok HVFA-SCC 60\% grafik hubungan beban dan lendutan menunjukan hubungan linear saat awal hingga pada beban tertentu kenaikan lendutan berubah dan tidak proposional dengan kenaikan pembebanan seperti di awal. Perubahan kenaikan lendutan ini diakibatkan pada balok HVFA-SCC 60\% sesaat sebelum runtuh akan muncul bukaan retak yang cukup besar sehingga berakibat pada kenaikan lendutan yang cukup besar namun beban cenderung tidak mengalami penambahan. Hal ini berbeda dengan balok normal yang tidak mengalami bukaan retak yang besar sehingga tidak terlalu terlihat tanda-tanda sesaat balok akan runtuh.

Dari data diatas didapatkan rata-rata gaya geser balok HVFA-SCC $60 \%$ adalah $26,125 \mathrm{kN}$ dan balok beton normal $21,500 \mathrm{kN}$, serta dapat dilihat bahwa gaya geser balok HVFA-SCC $60 \%$ lebih besar dibandingkan dengan balok beton normal.

\section{SIMPULAN}

Dari penelitian ini dapat diambil beberapa kesimpulan sebagai berikut :

1. Beban dan lendutan yang dapat diterima pada balok HVFA-SCC $60 \%$ lebih besar dibandingkan dengan balok beton normal.

2. Kapasitas geser balok HVFA-SCC 60\% lebih besar dibandingkan dengan kapasitas balok beton normal..

\section{UCAPAN TERIMAKASIH}

Penulis mengucapkan rasa terima kasih kepada kepada Bapak Agus Setiya Budi, S.T., M.T. dan Bapak Prof. Stefanus Adi Kristiawan, S.T., M.Sc., Ph.D. selaku pembimbing yang dengan penuh kesabaran telah memberi materi dan pemahaman sehingga menyempurnakan penyusunan. Rasa terima kasih penulis sampaikan kepada tim Gabungan Super selaku tim kerja bekerja keras dalam penelitian ini.

\section{REFERENSI}

Anonim. 1991. Tata Cara Perbitungan Struktur Beton Untuk Bangunan Gedung (SK SNI T-15-1991-03). Bandung. Anonim. 2002. The European Guidelines for Self-Compacting Concrete Specification, Production and Use. The European Federation of Specialist Construction Chemicals and Concrete Systems (EFNARC).

Anonim. 2005. The European Guidelines for Self-Compacting Concrete Specification, Production and Use. The European Federation of Specialist Construction Chemicals and Concrete Systems (EFNARC).

F. Ortiz Navas, Juan N.G., G. Leiva H., P. Serna, E. Cuenca. 2018. An Experimental Study on the Shear behaviour od Reinforced Concrete Beams With Macro-Synthetic Fibres. Construction and Building Materials 169 (2018).

Henry Apriyatno. 2010. Kapasitas geser Balok Beton Bertulang Dengan Polypropylene Fiber Sebesar 4\% Dari Volume Beton. Universitas Negeri Semarang.

James G. MacGregor. Reinforced Concrete Mechanics and Design. USA.

Kukun Rusyandi, dkk. 2012. Perancangan Beton Self Compacting Concrete (Beton Memadat Sendiri) Dengan Penambahan Fly Ash dan Structuro. Garut.

Laksmi Irianti. 2010. Kapasitas Ultimit dan Kapasitas Geser balok Beton Bertulang Mutu Tinggi Beragregat Batu Putih. Bandar Lampung.

Putut Sugianto. 2018. Kapasitas Lentur Balok Beton Bertulang High Volume Fly Ash Self Compacting Concrete (HVFASCC) Umur 28 Hari, Skripsi, Program Studi Teknik. Sipil Universitas Sebelas Maret. Surakarta.

Stephen P. Timoshenko, James M. Gere. Mekanika Bahan Jilid 1. Jakarta.

Van Piseth. 2015. Effect of Loading Rates on Shear Perfomance of RC Beams. Graduate School of Engineering Civil and Environmental Engineering, Hiroshima University.

Wiryanto Dewobroto. 2005. Simulasi Keruntuhan Balok Beton Bertulang Tanpa Sengkang Dengan ADINATM. Prosiding Seminar Nasional "Rekayasa Material dan Konstruksi Beton 2005", Jurusan Teknik Sipil ITENAS 4 Juni 2005. 